\title{
A Commutation Failure Suppression Control Method Based on the Controllable Operation Region of Hybrid Dual-Infeed HVDC System
}

\author{
Chao Xiao, Xiaofu Xiong, Jinxin Ouyang *, Getu Ma, Di Zheng and Ting Tang \\ State Key Laboratory of Power Transmission Equipment \& System Security and New Technology, \\ Chongqing University, Chongqing 40044, China; sngeet@163.com (C.X.); cquxxf@vip.sina.com (X.X.); \\ magetu269@gmail.com (G.M.); di.zh@foxmail.com (D.Z.); cq_tangting@163.com (T.T.) \\ * Correspondence: jinxinoy@163.com; Tel.: +86-186-2359-3294
}

Received: 7 February 2018; Accepted: 5 March 2018; Published: 7 March 2018

\begin{abstract}
With the increased use of high voltage direct current (HVDC) systems, line commutated converters (LCC-HVDC) and voltage source converters (VSC-HVDC) tend to feed into AC systems over short electrical distances. The flexible power control of VSC-HVDC systems provides an effective approach to suppress the commutation failure of LCC-HVDC systems. A suppression method, based on a controllable operation region, is proposed in this study to reduce the probability of commutation failure in a hybrid dual-infeed HVDC system. First, the quantitative transient reactive power control requirement of VSC-HVDC inverter that could fulfill the suppression control boundary condition of commutation failure was analyzed. Given the maximum current constraint of the VSC-HVDC inverter and the primary frequency modulation constraint of the sending-end grid, a controllable operation region of the hybrid dual-infeed HVDC system was proposed. Furthermore, a commutation failure suppression control method, based on the controllable operation region, was proposed to mitigate continuous commutation failure. Finally, the validity and accuracy of the proposed method was verified by the simulation of PSCAD/EMTDC. The proposed control method can realize reasonable use of the reactive power control capability of the VSC-HVDC system, which effectively improves immunity to commutation failure of the LCC-HVDC system under grid fault.
\end{abstract}

Keywords: line commutated converter for high voltage direct current (LCC-HVDC); voltage source converter for high voltage direct current (VSC-HVDC); hybrid dual-infeed HVDC system; controllable operation region; commutation failure

\section{Introduction}

Line commutated converters for high voltage direct currents (LCC-HVDC) have been widely applied due to their large capacity and low construction costs. Voltage source converters for high voltage direct current (VSC-HVDC) power transmission have also been rapidly developed because of their advantages decoupling the control of active and reactive power and no risk of commutation failure. With the increase in DC transmission projects, different types of HVDC systems tend to feed into power grids with short electrical distances. Thus, hybrid dual-infeed or multi-infeed HVDC systems have emerged worldwide [1,2].

Given that LCC-HVDCs are sensitive to AC grid voltage fluctuations, commutation failure is likely to occur at the inverter of the LCC-HVDC system during grid fault or voltage distortion, thereby leading to DC voltage drop, temporary overcurrent in the valves, and other adverse factors, which may affect the safe operation of the DC system. If the commutation failure cannot be eliminated effectively, then continuous commutation failure will occur, leading to converter blocking [3]. 
Over the past few years, considerable research on how to eliminate commutation failure in LCC-HVDC systems has been conducted [4-9]. In [4], a commutation failure prediction control algorithm based on the rapid detection of voltage dips in AC systems was proposed, which reduced the risk of commutation failure by reducing the firing angle of the inverter. On this basis, an improved commutation failure prediction control algorithm based on variations in DC current was proposed to improve immunity to commutation failure [5]. In [6], a power component fault detection method and improved voltage dependent current order limiter (VDCOL) were developed to mitigate commutation failure. This method mainly improved fault detection sensitivity and provided an advanced firing angle or enhanced current-order control methods to make the LCC-HVDC less susceptible to commutation failure. However, these methods rely heavily on the fault detection rate. Existing studies show that the first commutation failure is generally unavoidable and that continuous commutation failure after grid fault is the direct cause of converter blocking [7]. Focusing on the risk of continuous commutation failure, one study [8] achieved the suppression of continuous commutation failure by introducing a fuzzy controller to adjust the extinction angle at the inverter. In another study [9], a DC limiting strategy was designed based on virtual resistance to avoid continuous commutation failure according to variations in DC voltage.

In addition to the suppression of commutation failure by improving LCC-HVDC control, the addition of reactive power compensation devices has a good effect on commutation failure suppression. In [10], the performance of an LCC-HVDC system containing a static compensator (STATCOM) was investigated. Immunity to commutation failure was improved by adding the STATCOM to the AC side of the inverter. A STATCOM reactive power control strategy based on variation of the extinction angle of the inverter was designed in [11], and continuous commutation failure suppression capability was improved. However, reactive power compensation has some inherent drawbacks, for example, the response speed of static var compensators under grid fault is relatively slow, the reactive compensation capacity of STATCOM is limited, and the large capacity of STATCOM significantly increases the investment and operation cost of the power grid [12].

In a hybrid dual-infeed HVDC system, owing to active and reactive power decoupling control characteristics, VSC-HVDC systems have the ability to support grid voltage and provide an effective way to mitigate continuous commutation failure. Based on the calculation method of the effective short-circuit ratio (SCR) of the hybrid dual-infeed HVDC system, [13] proposed a VSC-HVDC reactive power control strategy to improve the voltage stability of the AC grid. Based on the variation of the extinction angle in the LCC-HVDC inverter during grid fault, a coordinated reactive-power control strategy based on extinction angle was proposed, which could reduce the commutation failure risk of the LCC-HVDC [14]. However, in the above studies, the reactive power control of VSC-HVDC has only been discussed qualitatively. The existing research does not fully consider the quantitative aspects of reactive power control and the frequency constraint of the sending-end grid.

In this study, a commutation failure suppression method of a hybrid dual-infeed HVDC system under grid fault was investigated, and the contribution of the reactive power control capacity of VSC-HVDCs to the mitigation of commutation failure was quantitatively analyzed. First, the reactive power demand required to avoid commutation failure under a grid fault was analyzed. Combined with the maximum current-limiting control constraint of the VSC-HVDC inverter and the primary frequency control capability of the sending-end grid, a controllable operation region and commutation failure suppression method was proposed. Finally, a hybrid dual-infeed HVDC system simulation model based on PSCAD/EMTDC simulation software was built to verify the effectiveness of the proposed control method. The simulation results showed that the proposed control method could improve the control capability of the VSC-HVDC system and effectively improve the suppression capability of continuous commutation failure in hybrid dual-infeed HVDC systems. 


\section{Hybrid Dual-Infeed HVDC System Model}

The structure of the hybrid dual-infeed HVDC transmission system, which consists of an LCC-HVDC and VSC-HVDC feeding into an AC grid, is shown in Figure 1. In Figure 1, the sending-end grids are represented by $S 1$ and $S 3$, and the receiving-end grids are represented by $S 2$ and $S 4$. The equivalent reactance of $S 2$ and $S 4$ is represented by $X_{S 2}$ and $X_{S 4}$, respectively. The equivalent electromotive force of $S 2$ and $S 4$ is represented by $E_{s 2} \angle 0$ and $E_{s 4} \angle 0$, respectively. $U_{B i} \angle \delta_{i}$ and $U_{B j} \angle \delta_{j}$ are the AC bus voltages of the VSC-HVDC and LCC-HVDC, respectively. $X_{t}$ is the equivalent reactance of the tie-line between buses $i$ and $j$.

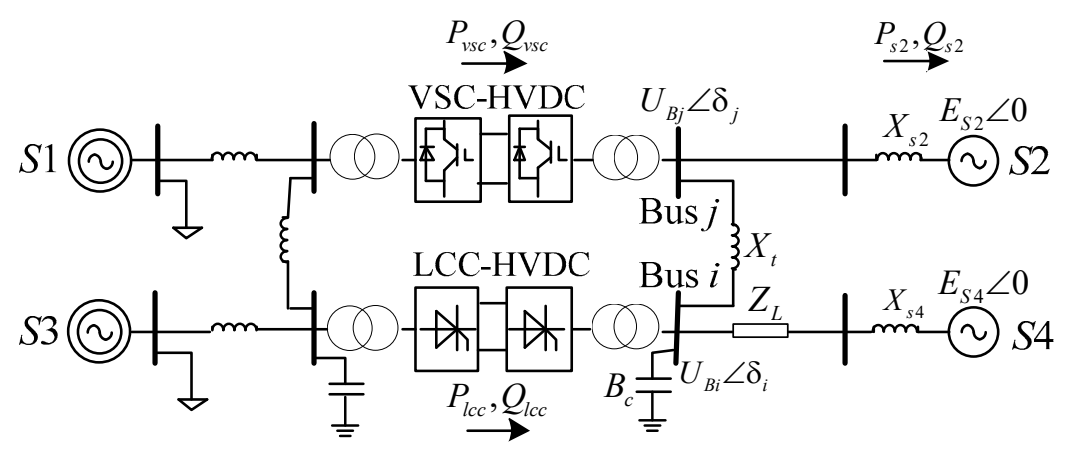

Figure 1. Diagram of the hybrid dual-infeed HVDC system.

In the LCC-HVDC system, thyristors are used as the commutation element, which have no self-turn-off capability. The LCC-HVDC system rectifier generally adopts constant DC current or constant power control, and the control strategy of the inverter is generally a constant extinction angle or constant DC current control. The DC current $I_{d}$ and DC voltage $U_{d}$ of the LCC-HVDC system can be expressed as follows [15]:

$$
\begin{aligned}
I_{d} & =\frac{U_{B i}[\cos \gamma-\cos (\gamma+\mu)]}{\sqrt{2} k X_{T}} \\
U_{d} & =\frac{3 \sqrt{2} U_{B i}}{\pi k} \cos \gamma-\frac{3}{\pi} X_{T} I_{d}
\end{aligned}
$$

where $U_{B i}$ is the voltage of the commutated bus at the inverter side, $\gamma$ is the extinction angle of the inverter, $\mu$ is the commutation overlap angle of the inverter, $k$ is the transformer ratio, and $X_{T}$ is the commutating reactance.

Under steady-state operating conditions, the reactive power, $Q_{d}$, consumed by the LCC-HVDC system can reach $40-60 \%$ of the transmitted active power [16]. This part of the reactive power consumption is usually provided by the reactive power compensation device and filter.

$$
\left\{\begin{array}{l}
P_{l c c}=U_{d} I_{d}=\frac{3 U_{B i}^{2}}{4 \pi X_{T}}(\cos (2 \gamma)-\cos (2 \gamma+2 \mu)) \\
Q_{l c c}=Q_{c}-Q_{d}=B_{c} U_{B i}^{2}-P_{l c c} \tan \varphi
\end{array}\right.
$$

where $P_{l c c}$ and $Q_{l c c}$ are the active and reactive power outputs of the LCC-HVDC inverter, respectively. $Q_{l c c}$ is positive when the reactive power is transmitted by the inverter to the AC grid. $Q_{l c c}$ is negative when the inverter absorbs reactive power from the AC grid. $Q_{c}$ is the reactive power output of the compensation device, $B_{c}$ is the equivalent susceptance of the reactive power compensation device, $Q_{d}$ is the reactive power consumption of the inverter, and $\varphi$ is the equivalent power factor angle.

In contrast to the control method of the LCC-HVDC system, the VSC-HVDC system adopts a voltage source converter based on fully controlled electronic devices, which can independently control active and reactive power and do not require reactive power compensation. Vector control is commonly adopted in the VSC-HVDC converter control strategy, which consists of the inner and outer loop current controls [17]. According to the grid voltage directional vector control method, the $d$-axis 
is oriented to the $\mathrm{AC}$ bus voltage, such that the active and reactive power outputs of the inverter can be expressed as follows:

$$
\left\{\begin{array}{l}
P_{v s c}=1.5 U_{B j} i_{d} \\
Q_{v s c}=-1.5 U_{B j} i_{q}
\end{array}\right.
$$

where $U_{B j}$ is the voltage of the AC bus at the inverter side of the VSC-HVDC; and $i_{d}$ and $i_{q}$ are the active and reactive currents, respectively. The active and reactive power control of the VSC-HVDC inverter can be controlled independently by adjusting $i_{d}$ and $i_{q}$, respectively.

Given that the electrical distance between different commutated buses in the multi-infeed DC system is relatively small, the amplitude and phase angle difference between the commutated bus voltages is usually small. Therefore, the power loss of the tie-line can be neglected. The active and reactive power outputs from the hybrid dual-infeed HVDC system via bus $i$ to the AC grid include the sum of the output powers of the VSC-HVDC inverter, the LCC-HVDC inverter, and the AC system S2.

$$
\left\{\begin{array}{l}
P_{s}=P_{v s c}+P_{l c c}-P_{s 2} \\
Q_{s}=Q_{v s c}+Q_{l c c}-Q_{s 2}
\end{array}\right.
$$

where $P_{s 2}$ and $Q_{s 2}$ are the active and reactive power outputs of the AC system $S 2$, respectively.

\section{Controllable Operation Region of the Hybrid Dual-Infeed HVDC System}

\subsection{Commutation Voltage Control Constraint (VCC)}

The extinction angle of the LCC-HVDC inverter can be calculated as follows [18]:

$$
\gamma=\arccos \left(\frac{\sqrt{2} k I_{d} X_{T}}{U_{B i}}+\cos \beta\right)
$$

where $\beta$ is the trigger advance angle of the inverter.

Short-circuit fault of the AC grid is the main cause of commutation failure. Generally, when the inverter extinction angle $\gamma$ is less than the critical extinction angle $\gamma_{\min }$ (approximately $7^{\circ}$ ), commutation failure will occur [19].

From Equation (6), the critical commutation voltage $U_{\text {lim }}$ under the critical extinction angle $\gamma_{\text {min }}$ can be expressed as follows:

$$
U_{\lim }=\frac{\sqrt{2} k I_{d} X_{T}}{\cos \gamma_{\min }-\cos \beta}
$$

When the voltage amplitude of the commutated bus is less than the critical commutation voltage, commutation failure will occur. The voltage amplitude of the commutated bus at the inverter side should fulfill the conditions in Equation (8) to eliminate the commutation failure of the LCC-HVDC inverter.

$$
U_{\lim } \leq U_{B i} \leq U_{\max }
$$

where $U_{\max }$ is the maximum allowable voltage amplitude of the commutated bus.

Figure 2 illustrates the equivalent network of the hybrid dual-infeed HVDC system under a three-phase short-circuit fault at the inverter side of the LCC-HVDC. $U_{g}$ is the voltage at fault point $g$, and $Z_{L}$ is the equivalent impedance between the commutated bus and fault point $g$. 


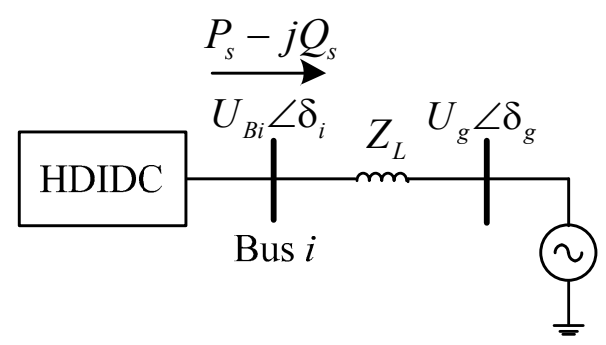

Figure 2. The equivalent network of the hybrid dual-infeed HVDC (HDIDC) system under grid fault.

The voltage vector at the commutated bus can be obtained as follows:

$$
\bar{U}_{B i}=\bar{U}_{g}+\overline{I Z}_{L}=\bar{U}_{g}+\frac{P_{s}+j Q_{s}}{U_{B i}^{*}} \bar{Z}_{L}
$$

where $\bar{U}_{B i}=U_{B i} \angle \delta_{i}, \bar{U}_{g}=U_{g} \angle \delta_{g}$. Given that the reactance component is larger than the resistance component in the HVAC transmission line and when the voltage vector is substituted into Equation (9), the constraint equation of voltage and power flowing at commutated bus $i$ can be derived as follows:

$$
X^{2} P_{s}^{2}+\left(X Q_{s}-U_{B i}^{2}\right)^{2}=U_{g}^{2} U_{B i}^{2}
$$

The combination of Equations (8) and (10) shows that, when the fault voltage decreases to $U_{g}$ to fulfill the amplitude boundary of the commutated bus voltage, the power output from the hybrid dual-infeed HVDC system via bus $i$ can be obtained as follows:

$$
\left\{\begin{aligned}
X^{2} P_{s}^{2}+\left(X Q_{s}-U_{\text {lim }}^{2}\right)^{2} & =U_{g}^{2} U_{\text {lim }}^{2} \\
X^{2} P_{s}^{2}+\left(X Q_{s}-U_{\text {rated }}^{2}\right)^{2} & =U_{g}^{2} U_{\max }^{2}
\end{aligned}\right.
$$

Combining Equations (5) and (11), the power equation can be derived as follows:

$$
\begin{gathered}
X^{2}\left(P_{v s c}+P_{l c c 1}+P_{s 2}\right)^{2}+\left(X Q_{v s c}+X Q_{l c c 1}+X Q_{s 2}-U_{l i m}^{2}\right)^{2}=U_{g}^{2} U_{l i m}^{2} \\
X^{2} P_{v s c}^{2}+\left(X Q_{v s c}-U_{\max }^{2}\right)^{2}=U_{g}^{2} U_{\max }^{2}
\end{gathered}
$$

where $P_{l c c 1}$ and $Q_{l c c 1}$ are the active and reactive power outputs of the LCC-HVDC inverter under the critical commutation voltage, which can be obtained by integrating the critical commutation voltage and critical extinction angle into Equation (3). The output of active and reactive power transferring from AC system S2 under the critical commutation voltage can be obtained using Equation (14).

$$
\left\{\begin{array}{l}
P_{s 2}=\frac{E_{s 2} U_{\lim } \sin \delta_{j}}{X_{s 2}} \\
Q_{s 2}=\frac{E_{s 2}^{2}-E_{s 2} U_{\lim } \cos \delta_{j}}{X_{s 2}}
\end{array}\right.
$$

According to the voltage and power constraints of Equations (12) and (13), the blue and red curves shown in Figure 3 represent the set of power operation points of the VSC-HVDC inverter, which can fulfill the critical commutation voltage amplitude and the maximum allowable voltage amplitude of the commutated bus in the $P Q$ coordinate, respectively. In Figure 3, the region surrounded by the blue and red dotted curves represents the power operating range of the VSC inverter that can avoid commutation failure. 


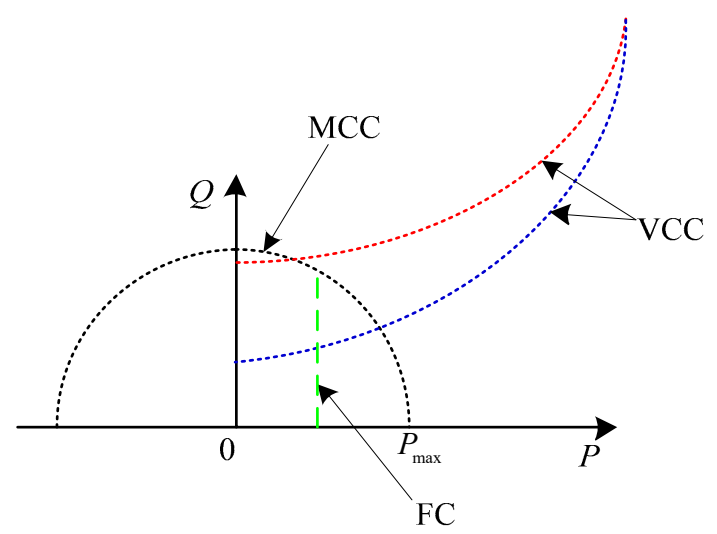

Figure 3. Controllable operation region of the VSC-HVDC inverter.

\subsection{Maximum Current Constraint (MCC) of VSC-HVDC}

Given that the overload capacity of the VSC-HVDC is small, a large transient current due to grid fault will damage the valves [20]. Therefore, current-limiting control must be implemented in the VSC inverter control system. Generally, the output current amplitude of the VSC is limited by the current reference of the inner current controller. The current-limiting amplitude $i_{\text {lim }}$ generally takes 1-1.5 times of the rated current. The active current component $i_{d}$ and reactive current component $i_{q}$ should fulfill the following relationship:

$$
i_{v s c}=\sqrt{i_{d}^{2}+i_{q}^{2}} \leq i_{\text {lim }}
$$

By combining Equations (4) and (15), the power circle of the VSC-HVDC converter under the maximum current-limiting constraint can be obtained by Equation (16) and the maximum current constraint (MCC), as shown in Figure 3.

$$
P_{v s c}^{2}+Q_{v s c}^{2} \leq\left(1.5 U_{B} i_{\text {lim }}\right)^{2}
$$

\subsection{Frequency Constraint (FC) of Sending-End Grid}

As the grid voltage decreases, in order to maintain the commutated bus voltage amplitude at the critical commutation voltage, the VSC-HVDC inverter needs to increase its reactive power output, which may cause a decrease in transmitted active power and the frequency of the sending-end grid to exceed the frequency regulation capability. The active power surplus of the sending-end grid $\Delta P$ under the critical commutation voltage can be expressed as follows:

$$
\Delta P=\left(P_{v s c}^{*}+P_{l c c}^{*}\right)-\left(P_{v s c}^{\prime}+P_{l c c 1}\right)
$$

where $P_{l c c}^{*}$ and $P_{v s c}^{*}$ are the rated active power transmitted by the LCC-HVDC and VSC-HVDC systems, respectively; and $P^{\prime}{ }_{\text {vsc }}$ is the maximum active power of the VSC-HVDC system under the critical commutation voltage.

The primary frequency modulation of the power grid utilizes a generator governor to regulate frequency and maintains the balance of load variation using the accumulator energy of the generators, which ensures that the frequency deviation maintains a normal range [21]. The hybrid dual-infeed HVDC system can be considered an active load for the sending-end grid. Given the primary frequency modulation capability of the sending-end grid, the corresponding maximum active power variation at the maximum allowable frequency deviation can be expressed as follows:

$$
\Delta P_{\max }=-K_{S} \cdot \Delta f_{\max }
$$


where $K_{S}$ is the unit power regulation of the sending-end grid, and $\Delta f_{\max }$ is the maximum frequency deviation of the sending-end grid.

The active power variation $\Delta P$ of the sending-end grid should be less than the maximum allowable frequency deviation $\Delta P_{\max }$ to fulfill the grid frequency deviation constraints. By combining Equations (17) and (18), the active power constraint of the VSC-HVDC system can be expressed as follows:

$$
P_{v s c}^{\prime} \geq P_{v s c}^{*}+P_{l c c}^{*}-P_{l c c 1}-K_{S} \cdot \Delta f_{\max }
$$

\section{Commutation Failure Suppression Method Based on Controllable Operation Region}

Based on the above analysis, the critical commutation voltage constraint (VCC) can be obtained by Equations (12) and (13). The power circle of the VSC-HVDC inverter under the maximum limiting current constraint (MCC) can be derived using Equation (16). The VSC-HVDC inverter active power constraint boundary, considering grid frequency constraints (FC), can be obtained using Equation (19). The intersection of the three constraints in the $P Q$ coordinate is the controllable operation region of the VSC-HVDC inverter, which can avoid commutation failure and fulfill the frequency constraint of the sending-end grid, as shown in the shaded area surrounded by points A, B, and C, in Figure 4.

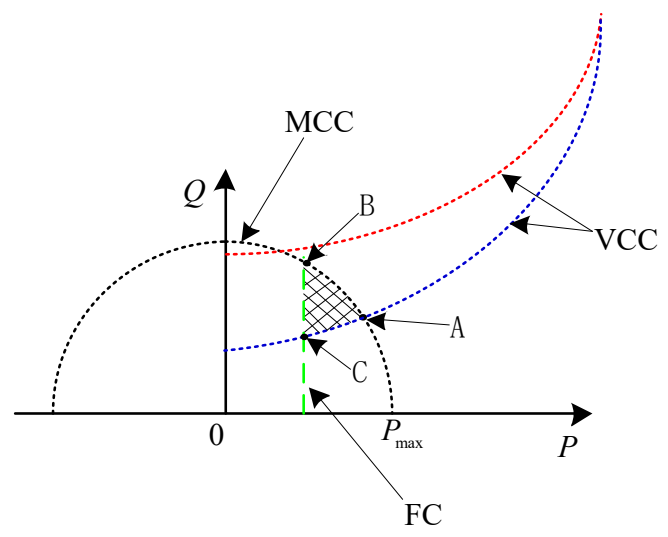

Figure 4. Controllable operation range of the VSC-HVDC inverter.

Considering the decrease in transmitted active power by the LCC-HVDC system, the power operation point A will not only fulfill the boundary of avoiding commutation failure, but will also assure the maximum active power transmission capability of the VSC-HVDC. In this study, the power operation point A was selected as the control reference value of the VSC inverter. By combining Equations (12) and (16), the maximum active power operation point of the controllable operation region, which can fulfill the critical commutation voltage, can be obtained, as shown by point $A$ in Figure 4 . The corresponding reactive power reference $Q^{\prime}{ }_{v s c}$ can be expressed as follows:

$$
Q_{v s c}^{\prime}=\frac{2 \lambda \mu \pm \sqrt{4 \lambda^{2} \mu^{2}-4\left(\mu^{2}+1\right)\left(\lambda^{2}-U_{\lim }^{2} i_{\lim }^{2}\right)}}{2\left(\mu^{2}+1\right)}=\frac{2 \lambda \mu \pm \sqrt{\Delta}}{2\left(\mu^{2}+1\right)}
$$

where

$$
\lambda=\frac{\left(X Q_{l c c 1}+U_{\lim }^{2}\right)^{2}+X^{2} U_{\lim }^{2} i_{\lim }^{2}+X^{2} P_{l c c 1}{ }^{2}-U_{g}^{2} U_{\lim }^{2}}{2 P_{l c c 1} X^{2}}, \mu=\frac{X Q_{l c c 1}+U_{\lim }^{2}}{P_{l c c 1} X}
$$

If $\Delta \geq 0$, then the controllable operation region that can avoid commutation failure exists. Combining Equations (16) and (19) yields the maximum reactive power operation point of the 
controllable operation region that fulfills the grid frequency constraint, as shown by point B in Figure 5 . The corresponding reactive power can be calculated as follows:

$$
Q_{v s c \max }=\sqrt{\left(1.5 U_{\lim } i_{\lim }\right)^{2}-\left(P_{v s c}^{*}+P_{l c c}^{*}-P_{l c c 1}-K_{S} \cdot \Delta f_{\max }\right)^{2}}
$$

By further substituting Equation (22) into Equation (12), the critical voltage $U_{g l i m}$ of the fault point under maximum reactive power $Q_{v s c \max }$ can be obtained.

$$
U_{g l i m}=\frac{X^{2}\left(P_{v s c}^{*}+P_{l c c}^{*}-P_{l c c 1}-K_{S} \cdot \Delta f_{\max }+P_{l c c 1}+P_{s 2}\right)^{2}+\left(X Q_{v s c \max }+X Q_{l c c 1}+X Q_{s 2}-U_{l i m}^{2}\right)^{2}}{U_{\lim }^{2}}
$$

If the voltage amplitude of the fault point is lower than $U_{g l i m}$, then the reactive control capacity of the VSC inverter cannot fulfill the condition of avoiding commutation failure and the frequency constraint.

Thus, the reactive current $i_{q}^{*}$ can be given by:

$$
i_{q}^{*}= \begin{cases}\frac{2 \lambda \mu \pm \sqrt{\Delta}}{3 U_{\lim }\left(\mu^{2}+1\right)}, & \Delta \geq 0 \\ i_{\lim ,} & \Delta<0\end{cases}
$$

Based on the solution of the controllable operation region, the proposed control principle in this study is as follows. Under normal conditions, the reference value of the inner loop current of the VSC-HVDC system is calculated by the outer active and reactive power loops. During the grid fault, the reactive power reference value of the VSC inverter is obtained according to Equation (20). Thus, the inner loop current reference is obtained using Equation (24). Then, the inner loop current reference is reset according to the calculation result by disconnecting the outer loop of the VSC inverter controller. The control block diagram of the proposed method is shown in Figure 5.

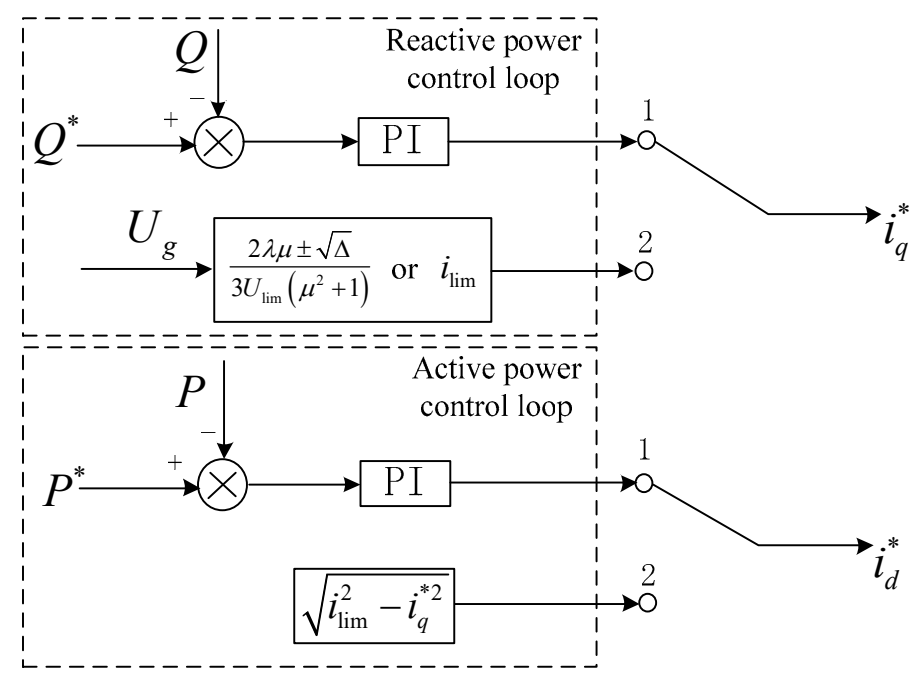

Figure 5. Control block diagram of the VSC inverter.

\section{Simulation Study}

A simulation model of the hybrid dual-infeed HVDC system was established in PSCAD/EMTDC to verify the validity of the commutation failure suppression method (Figure 1). The sending-end grids were represented by $S 1$ and $S 3$, which were modeled with synchronous generators models and static loads to investigate the frequency characteristic. The receiving-end grids $S 2$ and $S 4$ were modeled with the voltage sources and series impedance for the sake of simplicity, and the SCR of the receiving-end grid was 2.5. 
The CIGRE benchmark HVDC system was used in this paper and the LCC-HVDC system parameters were as follows: the rated power $P_{l c c}$ was $1000 \mathrm{MW}$, the rated DC voltage was $500 \mathrm{kV}$, the rated current was $2 \mathrm{kA}$, the inverter side converter bus rated voltage was $230 \mathrm{kV}$, the transformer ratio was $k=230 / 209.23$, the transformer short-circuit impedance percentage was $X_{T} \%=18 \%$, the inverter rated extinction angle $\gamma$ was $15^{\circ}$, and the trigger lead angle $\beta$ was $38.3^{\circ}$ [22].

Three-phase, two-level bridges based on the IGBT power devices were adopted in the simulation study and the VSC-HVDC system parameters were as follows: the rated power was $P_{v s c}=500 \mathrm{MW}$, the rated DC voltage was $500 \mathrm{kV}$, and the inverter side converter bus rated voltage was $230 \mathrm{kV}$. The maximum current of the converter was generally selected as 1.5 times the rated value. The rectifier station adopted constant DC voltage control and constant reactive power control, and the inverter station adopted the constant active and reactive power controls. The converter station was in unit power factor running status during normal operation. The base capacity was $1000 \mathrm{MVA}$, and the base voltage was $230 \mathrm{kV}$.

The maximum allowable voltage amplitude of the commutated bus $U_{\max }$ was set as 1.0 p.u. According to Equation (7) and the parameters of the LCC-HVDC system, the critical commutation voltage $U_{\text {lim }}$ could be calculated as 0.88 p.u. According to Equation (3), the active and reactive power outputs by the LCC-HVDC were 0.72 p.u. and -0.16 p.u. under the critical commutation voltage, respectively, whereas the active and reactive power outputs by the LCC-HVDC inverter were 1.0 p.u. and 0 p.u. under the maximum allowable voltage, respectively. The unit regulating power of the sending-end grid $K_{S}$ was set as $1200 \mathrm{MW} / \mathrm{Hz}$ and the operation error of primary frequency regulation as $0.3 \mathrm{~Hz}$. According to Equation (19), the transmitted active power $P_{v s c}$ of the VSC-HVDC system should have been larger than $0.42 \mathrm{p} . \mathrm{u}$. and the corresponding maximum reactive power $Q_{v s c m a x}$ was 0.509 p.u. According to Equation (23), the critical voltage at fault point $U_{g \text { lim }}$ of the VSC-HVDC could be obtained as 0.765 p.u.

\subsection{Validation of Control Effectiveness}

The three-phase short-circuit fault occurred at the $k$ point on the receiving-end grid. The fault occurred at the instant of $3 \mathrm{~s}$, and the voltage amplitude at the fault point $U_{g}$ decreased to $0.80 \mathrm{p} . \mathrm{u}$. By substituting the fault voltage and critical commutation voltage into Equations (12), (16) and (19), the controllable operation region could be obtained. Figure 6 shows the simulated controllable operation region of the hybrid dual-infeed HVDC system.

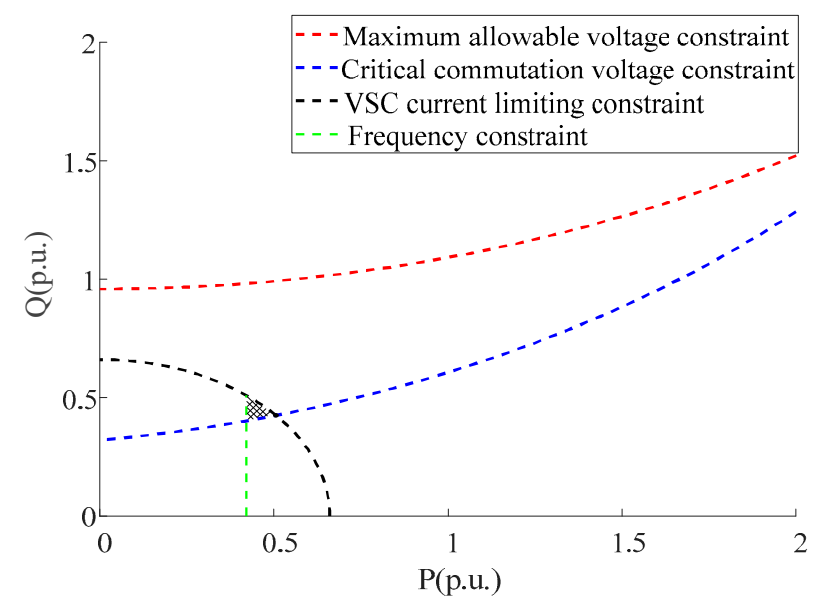

Figure 6. Controllable operation region of hybrid dual-infeed HVDC system when $U_{g}=0.8$ p.u.

According to Equation (20), the reactive power reference value of the VSC inverter could be calculated as 0.43 p.u. Based on the control block diagram shown in Figure 6, the inner loop current 
control reference of the VSC-HVDC inverter was switched to verify the effect of the commutation failure suppression method.

Figure 7 shows the simulated reactive power of the VSC inverter, commutated bus voltage of the LCC-HVDC, and extinction angle of the LCC-HVDC inverter. Without the switching control method, the reactive power reference of the VSC inverter maintained a constant value after the grid fault, and the commutated bus voltage amplitude decreased to 0.807 p.u. Commutation failure occurred three times at the LCC-HVDC inverter after the grid fault. Under the control method of this study, the VSC inverter delivered 430 Mvar reactive power after the grid fault, and the commutated bus voltage amplitude could be maintained at approximately 0.88 p.u. The commutation failure of the LCC-HVDC inverter occurred only at the instant of grid fault, which indicates that continuous commutation failure can be avoided by the proposed method.

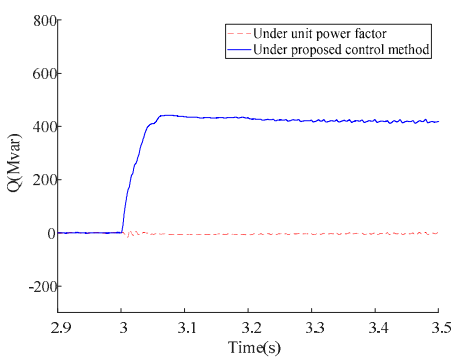

(a)

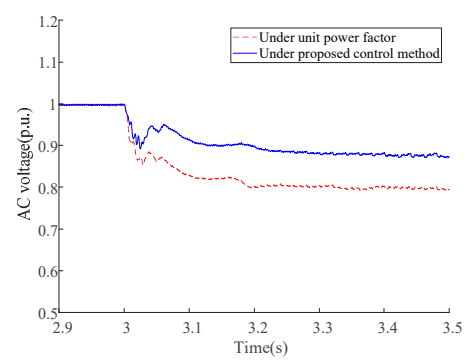

(b)

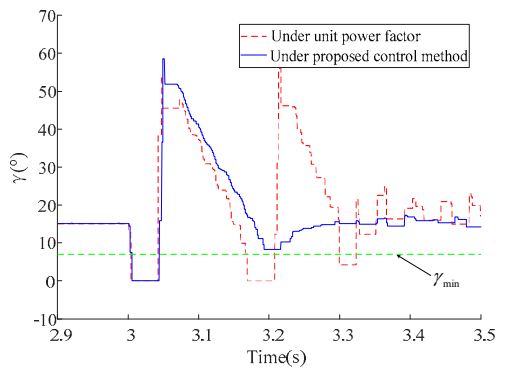

(c)

Figure 7. System performance under different control strategies. (a) Reactive power of the VSC-HVDC inverter; (b) Commutated bus voltage at the inverter side of the LCC-HVDC; (c) Extinction angle of the LCC-HVDC inverter.

\subsection{Validation of Controlled Operation Region}

The power operation points $A, A^{\prime}$, and $A^{\prime \prime}$ were selected as the control reference values to validate the controllable operation region, as shown in Figure 8. The active power and reactive power reference values of power operation point $A, A^{\prime}$, and $A^{\prime \prime}$ were ( 0.5 p.u., 0.43 p.u.), $(0.5$ p.u., 0.51 p.u.) and (0.56 p.u., 0.43 p.u.), respectively.

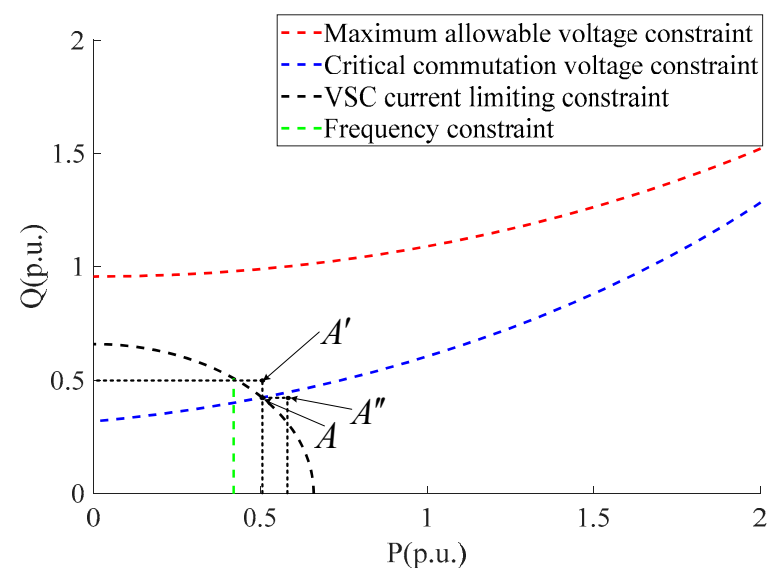

Figure 8. Controllable operation region of the hybrid dual-infeed HVDC system.

Figure 9 shows the simulated waveforms of the LCC-HVDC inverter extinction angle and AC current of VSC inverter under different operation points, where cases 1-3 are obtained by the power operation points $A, A^{\prime}$, and $A^{\prime \prime}$, respectively. In case 1 and case 2 , the commutation failure occurred only once at the instant of grid fault. However, in case 2 , the commutation failure occurred twice 
during the grid fault. The extinction angle of the second commutation failure was $5.8^{\circ}$, which was less than the critical extinction angle. Although the power operation points $A$ and $A^{\prime \prime}$ had the same reactive power reference value, power operation point $A^{\prime \prime}$ was located outside of the control operation region, which still led to the extinction angle being less than the critical extinction angle. Meanwhile, the AC current of the VSC inverter in case 1 was equal to $i_{\text {lim }}$, which fulfills these three constraints. However, only the commutation voltage control constraint and frequency constraint could be fulfilled in case 2 .

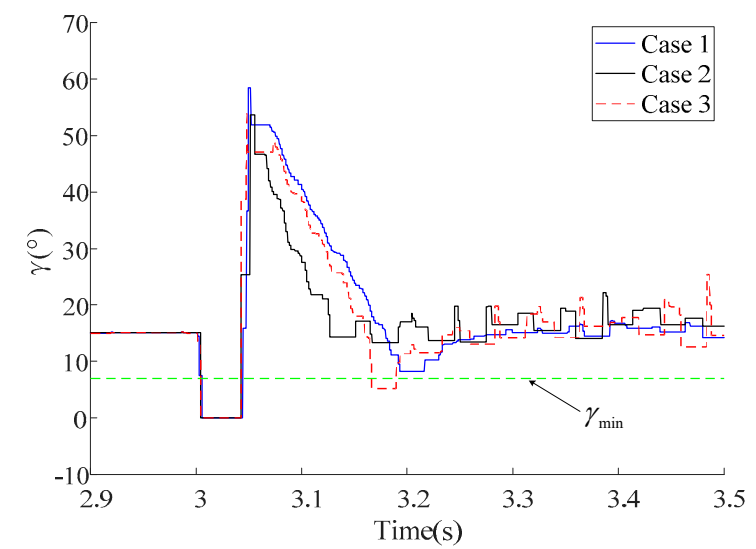

(a)

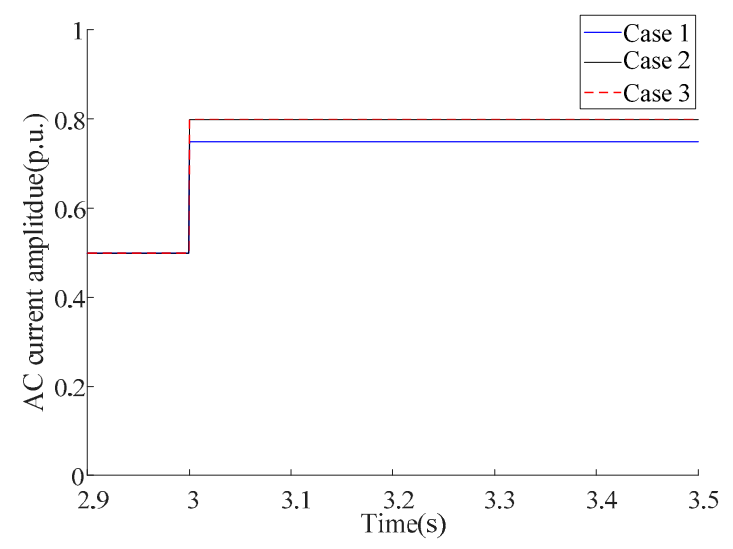

(b)

Figure 9. System performance under different power operation points. (a) Extinction angle of the LCC-HVDC inverter; (b) AC current amplitude of the VSC inverter side.

\subsection{Variation of the Controllable Operation Range under Different Voltage Drops}

According to Equation (23) and the HVDC system parameters, the critical voltage amplitude of fault point could be obtained as $0.762 \mathrm{p} . \mathrm{u}$. Figure 10 shows the controllable operation region under fault point voltage drops of $0.85,0.8$, and 0.77 p.u., and the corresponding reactive power operation points under different voltage drops, which were $0.29,0.43$, and 0.51 p.u., respectively. With the severity of the voltage drop, the VSC-HVDC needed to output more reactive power to fulfill the control requirement of critical commutation voltage to avoid the commutation failure of the LCC inverter. The controllable operation region of the hybrid dual-infeed HVDC system was gradually reduced. If the voltage amplitude is lower than $U_{g \mathrm{lim}}$, the controllable operation region that can fulfill VCC, MCC and FC does not exists.

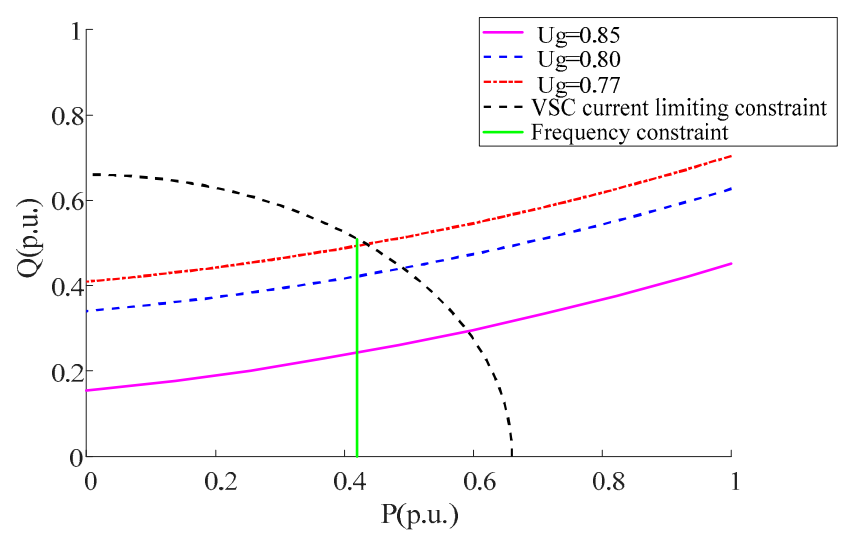

Figure 10. Variation of the controllable operation region under different voltage drops. 


\section{Conclusions}

In this study, investigating LCC-HVDC commutation failure in hybrid dual-infeed HVDC systems was the primary objective. The control requirements of the VSC-HVDC inverter that were necessary to fulfill the commutation failure boundary constraints in the hybrid dual-infeed HVDC system was analyzed. Given the maximum current constraint of the VSC inverters and the primary frequency modulation constraints of the sending-end grid, an analysis method involving the controllable operation region of the hybrid dual-infeed HVDC system was proposed. The capability of the VSC-HVDC system to suppress commutation failure in the hybrid dual-infeed HVDC system was also quantified. A suppression method of commutation failure, based on a controllable operation region, was proposed, which could reasonably utilize the transient reactive power control capability of the VSC-HVDC. This study provides a reference point for the control method of hybrid dual-infeed HVDC systems under grid fault.

Acknowledgments: This work was supported by the National Key Research and Development Program of China (2016YFB0900600), and the Technology Projects of State Grid Corporation of China (52094017000W).

Author Contributions: Chao Xiao, Xiaofu Xiong, and Jinxin Ouyang proposed the core idea and developed the models; Getu Ma and Di Zheng performed the simulations and analyzed the data; Ting Tang revised the paper; Chao Xiao and Jinxin Ouyang contributed to the writing of this manuscript.

Conflicts of Interest: The authors declare no conflict of interest.

\section{References}

1. Shilpa, G.; Manohar, P. Hybrid HVDC system for multi-infeed applications. In Proceedings of the IEEE International Conference on Emerging Trends in Communication, Control, Signal Processing \& Computing Applications, Bangalore, India, 10-11 October 2013; pp. 1-5.

2. Jacobson, D.A.N.; Wang, P.; Mohaddes, M.; Rashwan, M.; Ostash, R. A preliminary look at the feasibility of VSC HVdc in Manitoba. In Proceedings of the IEEE Electrical Power and Energy, Winnipeg, MB, Canada, 3-5 October 2011; pp. 80-85.

3. Liu, C.; Zhao, Y.; Wang, C.; Li, H.; Li, G. Superposition feature of the switching functions for the dynamic phasor model of the converters under commutation failure. IET Gener. Transm. Distrib. 2015, 9, 1448-1454. [CrossRef]

4. Zhang, L.; Dofnas, L. A novel method to mitigate commutation failures in HVDC systems. In Proceedings of the 2002 International Conference on Power System Technology, Kunming, China, 13-17 October 2002; pp. 51-56.

5. Wei, Z.; Yuan, Y.; Lei, X.; Wang, H.; Sun, G.; Sun, Y. Direct-Current Predictive Control Strategy for Inhibiting Commutation Failure in HVDC Converter. IEEE Trans. Power Syst. 2014, 29, 2409-2417. [CrossRef]

6. Guo, C.; Liu, Y.; Zhao, C.; Wei, X.; Xu, W. Power Component Fault Detection Method and Improved Current Order Limiter Control for Commutation Failure Mitigation in HVDC. IEEE Trans. Power Deliv. 2015, 30, 1585-1593. [CrossRef]

7. Son, H.I.; Kim, H.M. An Algorithm for Effective Mitigation of Commutation Failure in High-Voltage Direct-Current Systems. IEEE Trans. Power Deliv. 2016, 31, 1437-1446. [CrossRef]

8. Bauman, J.; Kazerani, M. Commutation Failure Reduction in HVDC Systems Using Adaptive Fuzzy Logic Controller. IEEE Trans. Power Syst. 2007, 22, 1995-2002. [CrossRef]

9. Guo, C.; Li, C.; Liu, Y.; Jiang, B.; Zhao, C.; Zhou, Q. A DC Current Limitation Control Method Based on Virtual-resistance to Mitigate the Continuous Commutation Failure for Conventional HVDC. Proc. CSEE 2016, 36, 4930-4937. [CrossRef]

10. Kim, C.K.; Sood, V.; Lee, S.J. Dynamic coordination strategies between HVDC and STATCOM. J. Power Electron. 2009, 9, 892-902. [CrossRef]

11. Zheng, Q.; Wang, X.; Fu, Y.; Yan, H.; Ou, Z.; Wang, G.; Wang, Y. A STATCOM compensation scheme for suppressing commutation failure in HVDC. In Proceedings of the IEEE Industrial Electronics Society Annual Conference, Florence, Italy, 23-26 October 2016; pp. 1081-1086. 
12. Xue, Y.; Zhang, X.P.; Yang, C. Elimination of Commutation Failures of LCC HVDC System with Controllable Capacitors. IEEE Trans. Power Syst. 2016, 31, 3289-3299. [CrossRef]

13. Liu, Y.; Chen, Z. A Flexible Power Control Method of VSC-HVDC Link for the Enhancement of Effective Short-Circuit Ratio in a Hybrid Multi-Infeed HVDC System. IEEE Trans. Power Syst. 2013, 28, 1568-1581. [CrossRef]

14. Chen, H.; Wang, Z.; Yang, Z.; Jiang, B.; Guo, C. Coordinated Reactive Power Control Approach for LCC-HVDC and VSC-HVDC in Hybrid Parallel HVDC System. Power Syst. Technol. 2015, 41, 1719-1725. [CrossRef]

15. Yang, H.; Cai, Z.; Zhu, L.; Zhou, B.; Zhang, D. A novel assessment index of LCC-HVDC system impact on short-term voltage stability of the receiving-end AC system. Electr. Power. Syst. Res. 2017, 142, 125-133. [CrossRef]

16. Dai, H.; Wang, Y.; Li, X.; Deng, H.; Min, Z. Characteristic Analysis of Reactive Power Compensation Device at HVDC Converter Station. In Proceedings of the Asia-Pacific Power and Energy Engineering Conference, Shanghai, China, 27-29 March 2012; pp. 1-5.

17. Song, S.; Kim, J.; Lee, J.; Jang, G. AC Transmission Emulation Control Strategies for the BTB VSC HVDC System in the Metropolitan Area of Seoul. Energies 2017, 10, 1143. [CrossRef]

18. Li, X.; Li, F.; Chen, S.; Li, Y.; Zou, Q.; Wu, Z.; Lin, S. An Improved Commutation Prediction Algorithm to Mitigate Commutation Failure in High Voltage Direct Current. Energies 2017, 10, 1481. [CrossRef]

19. Thio, C.V.; Davies, J.B.; Kent, K.L. Commutation failures in HVDC transmission systems. IEEE Trans. Power Deliv. 1996, 11, 946-957. [CrossRef]

20. Du, C.; Bollen, M.H.J.; Agneholm, E.; Sannino, A. A New Control Strategy of a VSC-HVDC System for High-Quality Supply of Industrial Plants. IEEE Trans. Power Deliv. 2007, 22, 2386-2394. [CrossRef]

21. Li, S.; Liao, Q.; Liu, D.; Cen, B. An improved under frequency load shedding strategy based on dynamic power flow tracing. Prot. Control Mod. Power Syst. 2017, 2, 1-8. [CrossRef]

22. Szechtman, M.; Wess, T.; Thio, C.V. A benchmark model for HVDC system studies. In Proceedings of the IET AC and DC Power Transmission International Conference, London, UK, 17-20 September 2002; pp. 374-378. 